\title{
EFFECT OF PETIOLE PHLOEM DISRUPTION ON STARCH AND MINERAL DISTRIBUTION IN SENESCING SOYBEAN LEAVES ${ }^{1}$
}

\author{
L. J. Wood, B. J. Murray, Y. Okatan, ${ }^{2}$ and L. D. Noodén \\ Biology Department, The University of Michigan, Ann Arbor, Michigan 48109-1048
}

\begin{abstract}
A B S T R A C T
Normally, starch (sugars) and minerals are redistributed from the leaves to the pods during monocarpic senescence in maturing soybean plants. Petiole phloem destruction (steam girdling), which blocked this redistribution by interrupting export through the petiole, altered the foliar senescence pattern producing a distinctive interveinal yellowing with green areas along the veins on pod-bearing plants. This suggests that blockage of the petiole phloem may cause nutrients to accumulate in the green zones along the leaf veins instead of being redistributed to the pods. In the leaves of untreated plants, starch showed the same distribution pattern as chlorophyll; however, starch was preserved in yellow areas as well as the green zones of the steam-girdled leaves. Mineral analyses of the veinal and interveinal zones of treated leaves and controls showed that the veinal green zones and interveinal yellowing in treated plants were not respectively enriched and depleted in minerals corresponding to a redistribution of minerals within the leaves. Depodding also blocked leaf yellowing, net mineral redistribution and starch breakdown. Thus, the pods are able to induce chlorophyll breakdown without net mineral redistribution or starch loss in leaves with petiole phloem destruction. This shows that chlorophyll breakdown is not obligatorily coupled with mineral redistribution or starch breakdown.
\end{abstract}

SENESCENCE IS the orderly and well-coordinated degeneration leading to the death of a cell, tissue or plant (Leopold, 1961; Noodén and Leopold, 1978; Noodén and Thompson, 1985). The rapid degeneration of the soybean plant during its reproductive phase (monocarpic senescence) is coupled with development of the pods which exert their influence on the leaves (Leopold, Niedergang-Kamien and Janick, 1959; Lindoo and Noodén, 1977; Noodén 1980). Senescence consists of a syndrome of changes in which chlorophyll loss, protein breakdown and mineral mobilization are prominent features (Noodén, 1980, 1984, 1985). Depodding blocks the exodus of minerals from the leaves just as it prevents the rapid degeneration leading to death (Leopold et al., 1959; Derman, Rupp and Noodén, 1978; Noodén, 1984). It has been considered that nutrient diversion (withdrawal) might be a primary cause of leaf yellowing (Noodén, 1980), but phloem destruction which blocks withdrawal of nutrients from the blades does not prevent pod induction of leaf senescence (Noodén and Murray, 1982). Petiole girdling does not prevent the pods from inducing chlorophyll breakdown; however, the leaves with

\footnotetext{
' Received for publication 8 May 1985; revision accepted 6 March 1986.

Supported in part by NSF Grant PCM-83-2707.

2 Present address: Dept. of Botany, University of Istanbul, Suleymaniye, Istanbul, Turkey.
}

girdled petioles (and adjacent pods) tend to retain chlorophyll in their veinal regions. This produces a distinctive pattern of interveinal yellowing with green zones $3-5 \mathrm{~mm}$ on each side of the major veins.

Since redistribution (exodus) of minerals including $\mathrm{N}$ from the leaves may be an important component of the senescence syndrome (Noodén, 1980) and redistribution may take place within a leaf(Greenway and Gunn, 1966; Mishra and Gaur, 1972), it seemed important to determine whether or not the green veinal pattern in the leaves with girdled petioles (exodus through the phloem blocked) represented redistribution within the leaves with an accumulation of nutrients along the main veins.

MATERIALS AND METHODS-Plant culture. Soybean seeds [Glycine max (L.) Merrill cv. Anoka] were inoculated with Rhizobium and grown in soil on a greenhouse bench with an 18-hr photoperiod until the second trifoliate leaf had expanded and thence under 10-hr (short day) photoperiods with $27 \mathrm{C}$ day and $21 \mathrm{C}$ night temperatures as described previously (Lindoo and Noodén, 1976). Harvests were made at early-mid podfill (when the seeds in the most advanced pod in a cluster nearly filled the seed cavity), which occurred about short day (SD) 64, and at late podfill, the start of leaf yellowing, which took place about SD 88 . 
TABLE 1. Effect of petiole phloem destruction on changes in fresh and dry wt distribution in veinal and interveinal regions and area of leaf blades during podfill. Steam girdling was done at early-mid podfill (Short Day 64). S.E. are shown

\begin{tabular}{|c|c|c|c|c|c|c|}
\hline & \multicolumn{2}{|c|}{$\begin{array}{l}\text { Early-mid podfill } \\
\text { (Short Day } 64)\end{array}$} & \multicolumn{2}{|c|}{$\begin{array}{l}\text { Late podfill } \\
\text { (Short Day 88) }\end{array}$} & \multicolumn{2}{|c|}{$\begin{array}{l}\text { Late podfill, with girdled petiole } \\
\text { (Short Day 88) }\end{array}$} \\
\hline & Veinal & Interv. & Veinal & Interv. & Veinal & Interv. \\
\hline $\begin{array}{l}\mathrm{g} \text { fresh wt } / 3 \text { leaflets } \\
\mathrm{g} \text { dry wt } 3 \text { leaflets }\end{array}$ & $\begin{array}{l}1.36 \pm 0.03 \\
0.38 \pm 0.01\end{array}$ & $\begin{array}{l}0.60 \pm 0.01 \\
0.17 \pm 0.01\end{array}$ & $\begin{array}{l}1.72 \pm 0.11 \\
0.23 \pm 0.08\end{array}$ & $\begin{array}{l}0.85 \pm 0.04 \\
0.13 \pm 0.01\end{array}$ & $\begin{array}{l}1.53 \pm 0.12 \\
0.53 \pm 0.04\end{array}$ & $\begin{array}{l}0.87 \pm 0.03 \\
0.36 \pm 0.02\end{array}$ \\
\hline $\begin{array}{l}\text { g dry wt/g fresh wt } \\
\text { Area }\left(\mathrm{cm}^{2}\right) / 3 \text { leaflets }\end{array}$ & \multicolumn{2}{|c|}{$\begin{array}{c}0.28 \\
114 \pm 5\end{array}$} & \multicolumn{2}{|c|}{$\begin{array}{c}0.14 \\
146 \pm 8\end{array}$} & \multicolumn{2}{|c|}{$\begin{array}{c}0.37 \\
98 \pm 3\end{array}$} \\
\hline
\end{tabular}

Steam girdling-At early-mid podfill (SD 64 ), a $1 \mathrm{~cm}$ zone in the petiole of a leaf in the middle of the pod-bearing zone of the plant was heated with a jet of steam for about $1 \mathrm{~min}$. During the treatment, the petiole was rotated to heat all sides evenly and precautions were taken to protect the adjacent blade and stem from the steam. Immediately after heating, the treated petiole was fastened to a wooden splint with cellophane tape to prevent bending. In general, there was no sign of heat damage to the plant and no indication (e.g., wilting) that water conductivity was affected.

Starch staining - Immediately before staining for starch, the leaves were cut off and photographed. Next, they were immersed in boiling $\mathrm{H}_{2} \mathrm{O}$ for $25 \mathrm{~min}$ followed by extraction of the dominant pigments with boiling $95 \%$ $(v / v)$ ethanol. In order to stain the starch, the depigmented leaves were placed in boiling iodine solution $\left(0.8 \% \mathrm{w} / \mathrm{v} \mathrm{KI}\right.$ and $0.4 \% \mathrm{w} / \mathrm{v} \mathrm{I}_{2}$ in distilled water, Hemberg, 1975) for about $20 \mathrm{~min}$. Then, the leaves were soaked in $50 \%$ ethanol for 2 days followed by $20 \%(v / v)$ ethanol for about 2 days.

Separation of veinal and interveinal zonesEach leaflet from the controls and petiole-girdled plants was cut into veinal and interveinal zones corresponding to the green and yellow areas of the petiole-girdled leaves shown in Fig. 1. Dry wts were then taken following at least $24 \mathrm{hr}$ in a drying oven at $75 \mathrm{C}$.

Mineral analysis-The mineral contents were determined by the Plant Analysis Laboratory, Department of Horticulture, Oregon State Univ., Corvallis, OR using a Jerral Ash ICAP 9000 inductively-coupled argon plasma spectrophotometer.

RESUlTs-Fresh and dry wt distributions in the leaves-These parameters seem essential as references for the mineral analysis data; however, they also changed. Comparing early mid podfill (SD 64) with late podfill (SD 88), the start of leaf yellowing (Table 1) shows an increase in fresh wt in both the veinal and interveinal regions but a decrease in dry wt. The increase in fresh wt (and blade area) probably represents growth, while the decreased dry wt may be due to export of materials from the leaves. Phloem destruction (steam girdling of the petiole) inhibited the fresh wt increase in the veinal region, and it not only prevented the decrease in dry wt but also promoted accumulation in both the veinal and interveinal areas. Apparently, the materials (starch?) which comprise the dry wt fail to be exported from the girdled leaf, and accumulation continues. In addition, the fresh wt increase in girdled leaves, though less than that in the control leaves, indicates that the xylem remains functional. Furthermore, these leaves do not wilt.

Mineral redistribution from the blades - Five general patterns of change in mineral levels were observed for the controls relative to the effect of petiole phloem destruction (Table 2). 1) The amounts of phosphorus, sulfur, iron, sodium and copper decreased in the control leaves by the time yellowing had started (late podfill, $S D 88$ ) as compared to the $T=0$ leaves (early-mid podfill, SD 64). Petiole girdling at short day 64 prevented the decrease in the foliar levels of these minerals. 2) Molybdenum and potassium levels decreased in the controls, but petiole girdling produced a large increase. 3) The amount of zinc decreased in the control leaves but declined even more in the girdled leaves. 4) The amounts of calcium and manganese in the leaves of the control plants increased, but petiole girdling prevented this. 5) The amounts of magnesium and boron rose in the controls, and phloem destruction had little effect in preventing this increase. The decrease of $\mathrm{Zn}$ even in the girdled leaves warrants special note, because it is difficult to explain.

Mineral distribution within the leaves-On a fresh wt basis, the values for sulfur, sodium, 
TABLE 2. Changes in mineral content of leaf blades during podfill and effect of petiole phloem destruction at early-mid podfill. Same leaves as in Table 1. S.E. are shown

\begin{tabular}{lccc}
\hline \hline Element & $\begin{array}{c}\text { Early-mid podfill } \\
\text { (Short Day 64) }\end{array}$ & $\begin{array}{c}\text { Late podfill } \\
\text { (Short Day 88) }\end{array}$ & $\begin{array}{c}\text { Late podfill, } \\
\text { with girdled } \\
\text { petiole } \\
\text { (Short Day 88) }\end{array}$ \\
\hline & & $\mathrm{mg} / \mathrm{g}$ fresh wt \\
$\mathrm{P}$ & $1.32 \pm 0.15$ & $0.25 \pm 0.03$ & $1.24 \pm 0.11$ \\
$\mathrm{~K}$ & $2.45 \pm 0.63$ & $0.27 \pm 0.07$ & $7.26 \pm 0.48$ \\
$\mathrm{Ca}$ & $4.54 \pm 0.45$ & $10.2 \pm 1.2$ & $5.50 \pm 0.41$ \\
$\mathrm{Mg}$ & $1.29 \pm 0.10$ & $1.67 \pm 0.23$ & $1.69 \pm 0.11$ \\
$\mathrm{~S}$ & $0.91 \pm 0.07$ & $0.53 \pm 0.05$ & $1.24 \pm 0.08$ \\
& & $\mu \mathrm{g} / \mathrm{g}$ fresh wt & \\
$\mathrm{Mn}$ & $36.3 \pm 2.1$ & $56.2 \pm 5.8$ & $37.6 \pm 2.9$ \\
$\mathrm{Fe}$ & $48.9 \pm 3.9$ & $30.2 \pm 2.9$ & $50.4 \pm 3.4$ \\
$\mathrm{Cu}$ & $1.01 \pm 0.13$ & $0.87 \pm 0.09$ & $1.33 \pm 0.07$ \\
$\mathrm{~B}$ & $17.4 \pm 1.2$ & $24.2 \pm 2.1$ & $26.6 \pm 1.0$ \\
$\mathrm{Zn}$ & $45.1 \pm 4.2$ & $21.6 \pm 2.4$ & $17.2 \pm 1.4$ \\
$\mathrm{Mo}$ & $0.45 \pm 0.05$ & $0.088 \pm 0.01$ & $1.10 \pm 0.11$ \\
$\mathrm{Na}$ & $35.3 \pm 3.2$ & $24.9 \pm 2.7$ & $43.1 \pm 1.8$ \\
\hline
\end{tabular}

boron, iron and manganese at early-mid podfill were slightly higher in the interveinal regions compared with the veinal regions (Table 3). The other minerals were present at about the same levels in the veinal and interveinal regions. At late podfill, these relative distributions were maintained except that phosphorus, calcium and zinc were also present in larger amounts in the interveinal regions, while the potassium level was less in the interveinal region. Although petiole girdling prevented these changes in relative distribution and prevented the decrease in levels of some minerals in the leaf blades, it did not cause preferential accumulation along the veins.

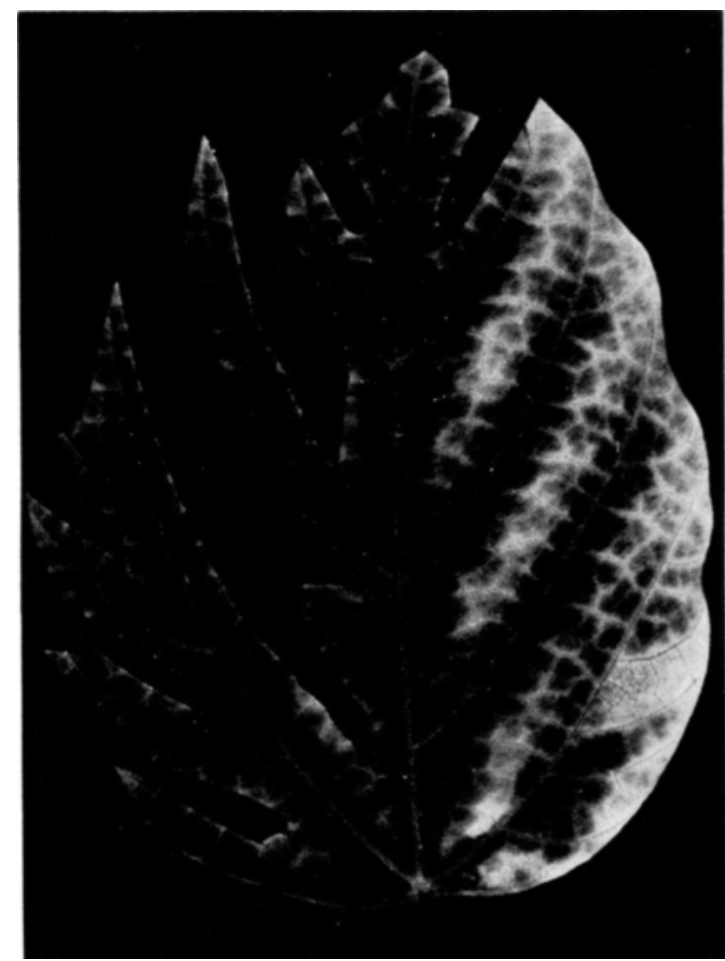

Fig. 1. Petiole-girdled leaf displaying special pattern of yellow (interveinal) and green (veinal) regions. For analyses, the veinal and interveinal regions were cut out as shown.

Pattern of starch loss in normal versus petiole-girdled leaves-In the leaves of normal, podded plants, starch loss followed the same pattern as chlorophyll; starch staining was evident only in areas that were green prior to staining. Starch was especially prominent close

TABLE 3. Changes in mineral distribution between veinal and interveinal regions of leaf blades during podfill and effect of petiole phloem destruction. Girdled at early-mid podfill. Same leaves as in Table 1. S.E. are shown

\begin{tabular}{|c|c|c|c|c|c|c|}
\hline \multirow[b]{2}{*}{ Element } & \multicolumn{2}{|c|}{$\begin{array}{l}\text { Early-mid podfill } \\
\text { (Short Day 64) }\end{array}$} & \multicolumn{2}{|c|}{$\begin{array}{c}\text { Late podfill } \\
\text { (Short Day } 88 \text { ) }\end{array}$} & \multicolumn{2}{|c|}{$\begin{array}{l}\text { Late podfill, with girdled petiole } \\
\text { (Short Day 88) }\end{array}$} \\
\hline & Veinal & Interv. & Veinal & Interv. & Veinal & Interv. \\
\hline & \multicolumn{6}{|c|}{$\mathrm{mg} / \mathrm{g}$ fresh wt } \\
\hline $\mathbf{P}$ & $0.70 \pm 0.10$ & $0.63 \pm 0.06$ & $0.073 \pm 0.004$ & $0.15 \pm 0.01$ & $0.52 \pm 0.06$ & $0.50 \pm 0.06$ \\
\hline $\mathbf{K}$ & $0.95 \pm 1.0$ & $1.9 \pm 0.11$ & $0.14 \pm 0.05$ & $0.019 \pm 0.01$ & $2.9 \pm 0.30$ & $3.3 \pm 0.30$ \\
\hline $\mathrm{Ca}$ & $2.4 \pm 0.14$ & $2.1 \pm 0.09$ & $3.7 \pm 0.12$ & $4.5 \pm 0.15$ & $2.2 \pm 0.21$ & $2.5 \pm 0.40$ \\
\hline $\mathrm{Mg}$ & $0.64 \pm 0.03$ & $0.70 \pm 0.06$ & $0.62 \pm 0.21$ & $0.66 \pm 0.01$ & $0.67 \pm 0.06$ & $0.79 \pm 0.11$ \\
\hline \multirow[t]{2}{*}{$\mathrm{S}$} & $0.44 \pm 0.01$ & $0.51 \pm 0.01$ & $0.17 \pm 0.06$ & $0.26 \pm 0.01$ & $0.48 \pm 0.04$ & $0.57 \pm 0.08$ \\
\hline & \multicolumn{6}{|c|}{$\mu \mathrm{g} / \mathrm{g}$ fresh wt } \\
\hline $\mathrm{Mn}$ & $16 \pm 1.9$ & $24 \pm 3.1$ & $17 \pm 6.6$ & $35 \pm 3.5$ & $15 \pm 2.5$ & $17 \pm 1.1$ \\
\hline $\mathrm{Fe}$ & $24 \pm 1.8$ & $27 \pm 0.40$ & $9.9 \pm 3.1$ & $15 \pm 1.6$ & $20 \pm 1.3$ & $22 \pm 1.7$ \\
\hline $\mathrm{Cu}$ & $0.58 \pm 1.8$ & $0.38 \pm 0.05$ & $0.33 \pm 0.04$ & $0.36 \pm 0.13$ & $0.50 \pm 0.02$ & $0.65 \pm 0.10$ \\
\hline B & $8 \pm 0.20$ & $10 \pm 0.60$ & $7.2 \pm 2.3$ & $13 \pm 1.0$ & $9.7 \pm 0.22$ & $14 \pm 1.2$ \\
\hline $\mathrm{Zn}$ & $8.0 \pm 0.70$ & $8.6 \pm 0.3$ & $7.2 \pm 2.7$ & $11 \pm 1.4$ & $6.9 \pm 0.80$ & $7.5 \pm 1.0$ \\
\hline Mo & $0.21 \pm 0.07$ & $0.28 \pm 0.05$ & $0.034 \pm 0.01$ & $0.033 \pm 0.01$ & $0.46 \pm 0.08$ & $0.44 \pm 0.09$ \\
\hline $\mathrm{Na}$ & $16 \pm 3.7$ & $22 \pm 2.6$ & $8.1 \pm 3.1$ & $13 \pm 2.3$ & $15 \pm 3.0$ & $24 \pm 2.5$ \\
\hline
\end{tabular}



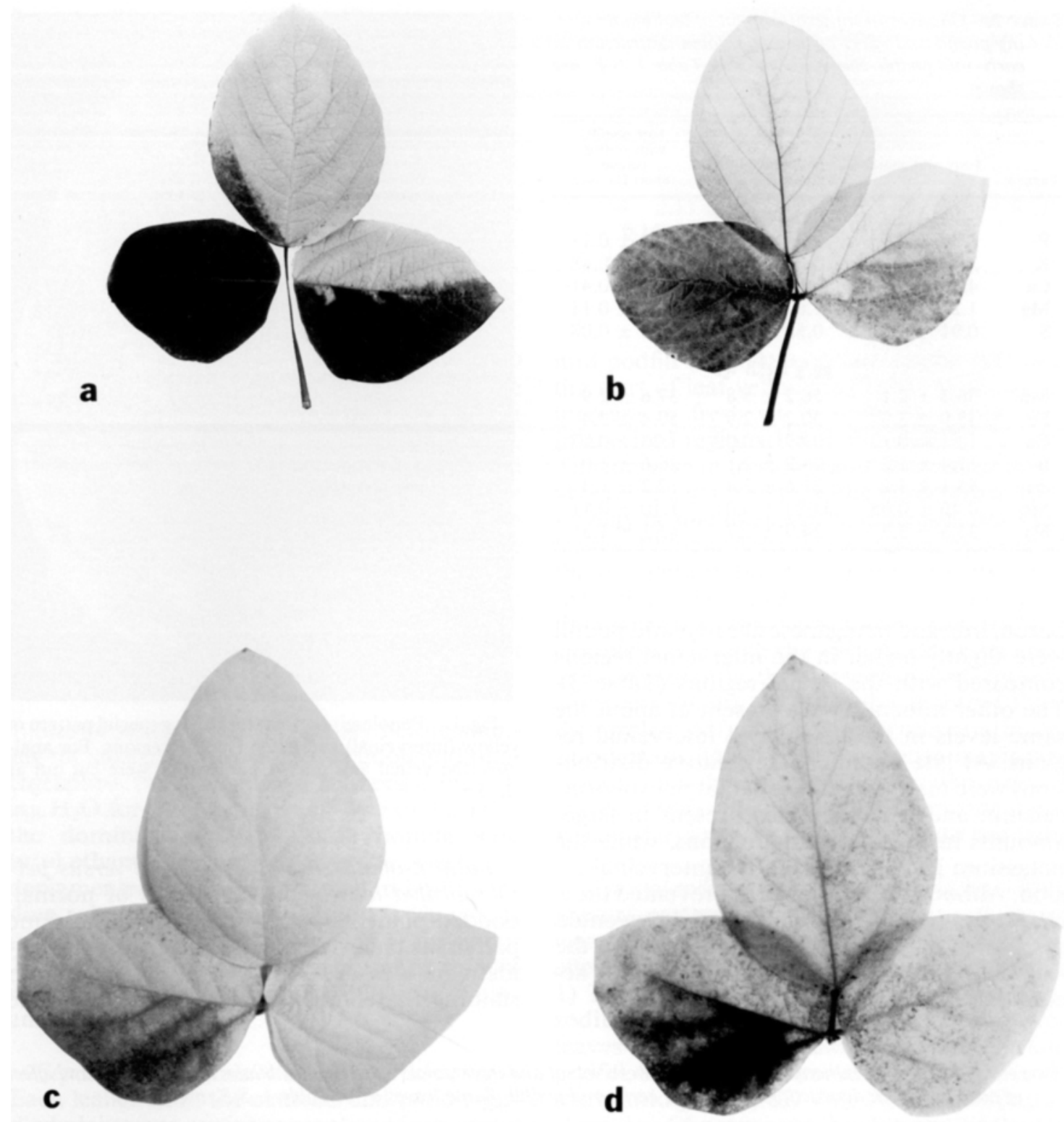

Fig. 2. Comparison of chlorophyll (a and $c$ ) and starch (b and d) distribution in normal leaves at intermediate stages of yellowing. The leaves are shown in a natural state ( $a$ and $c$ ) and after $I_{2}$ staining for starch (b and d, respectively).

to the main veins and in the petiole (Fig. 2ad).

In petiole-girdled leaves, starch did not follow the chlorophyll pattern (Fig. 3a-b). The entire leaf was uniformly stained with iodine except the portion of the petiole (not shown) which was girdled.

Discussion-A distinctive yellowing pattern-During the normal course of monocarpic senescence in soybean, the leaves show chlorophyll loss over the main veins (vein yellow- ing) long before visible yellow zones appear in the lamina (Benner and Noodén, 1984). Next, yellowing starts over the minor veins and then in the lamina between the veins, so the net result is yellowing of the interveinal tissue spreading back to the main veins. The yellowing around the minor veins is readily visible in Fig. 1. Often, the visible yellowing of these leaflets is not uniform; individual leaflets in a leaf may differ and leaflets may show sectoring as in Fig. 2. Steam girdling which disrupts the phloem in the petiole of a soybean leaf 

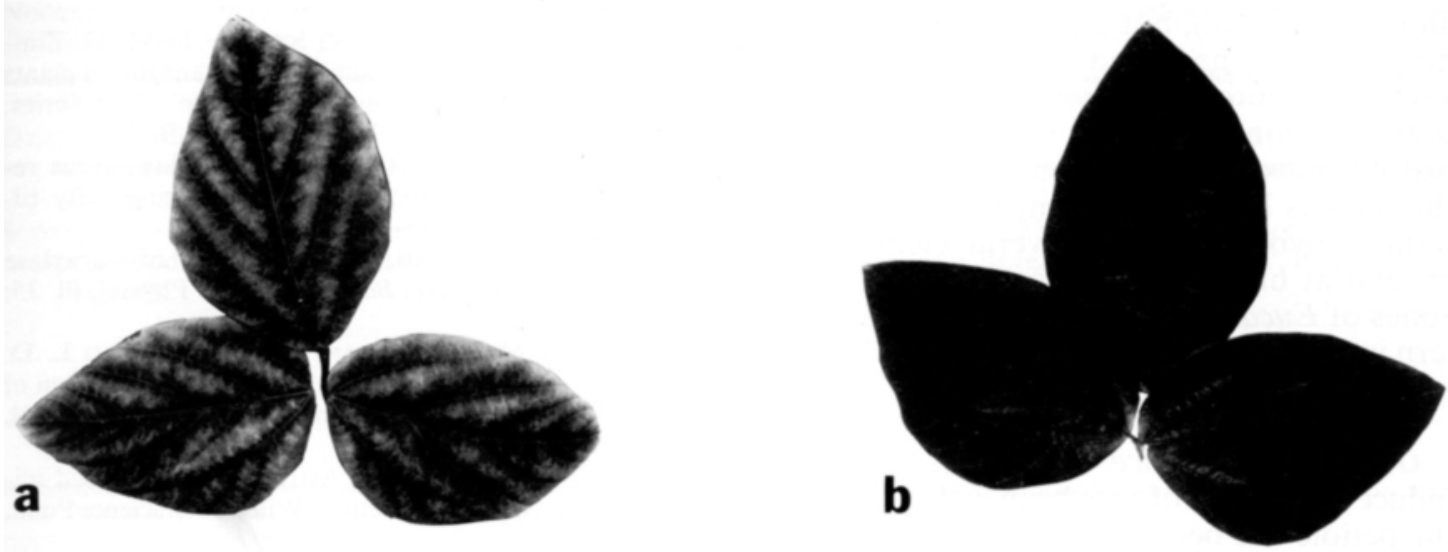

Fig. 3. a. Steam-girdled leaf displaying the special pattern of green veinal and yellow interveinal regions. b. Steamgirdled leaf showing pattern of starch distribution $\left(\mathbf{I}_{2}\right.$ staining).

undergoing monocarpic senescence does not prevent leaf yellowing. These girdled leaves, however, develop a characteristic pattern in which the interveinal regions turn yellow and veinal regions tend to retain their green color. The treatment (petiole girdling) does not itself cause this pattern to develop, since similar treatment of a leaf on a depodded plant does not induce the pattern; these leaves remain uniformly green (Noodén and Murray, 1982). Therefore, the pods induce the development of this distinctive pattern. Normal leaves on pod-bearing soybean plants show a similar, but much less pronounced and very short-lived, pattern during early yellowing. The same distinctive pattern with green along the main veins of yellow leaves has, however, been observed during senescence in the leaves of a few species (DeLuca d'Oro and Trippi, 1980; Simon, 1967).

In addition, diverse factors such as disease (Sinclair, 1982), petiole bending (Scott and Aldrich, 1970) and certain herbicides (Klingman and Ashton, 1975) can induce this pattern. These patterns also develop under certain mineral deficiencies, for example $\mathrm{Fe}, \mathrm{Mg}, \mathrm{Mn}, \mathrm{Zn}$, $\mathrm{B}$ and to a lesser extent K (Sprague, 1964). Thus, deficiencies involving minerals with differing mobilities may cause the interveinal yellowing pattern. No common denominator is evident among these different factors.

Testing a possible mechanism of generating the distinctive pattern in petiole-girdled leavesIn soybeans undergoing monocarpic senescence, minerals move out of the leaves, mainly to the pods (Derman et al., 1978; Loehwing,
1951; Noodén, 1980; Williams, 1955). Likewise, starch is broken down and the sugars are apparently translocated to the pods (Okatan, Kahanak and Noodén, 1981). Since most (if not all) materials passing out of a leaf must move out through the petiole via the phloem, blockage of this route by phloem destruction (steam girdling) could cause a pile up of materials along the veins in the leaf blade. Because some mineral deficiencies can produce a similar pattern of leaf yellowing (Sprague, 1964) and a diminished (or increased) mineral nutrient supply can accelerate (or retard) leaf senescence (Neumann, Tucker and Noodén, 1983; Noodén, 1984), it appears possible that this distinctive pattern could be caused by withdrawal or release of mineral nutrients from the interveinal regions under the influence of the pods with an accumulation along the veins due to phloem blockage. Moreover, redistribution of mineral nutrients within the leaves has been observed in other species, but these movements are from apex to base (Greenway and Gunn, 1966; Mishra and Gaur, 1972). A somewhat similar pattern has been reported for bean leaves (Nakata and Leopold, 1967); however, this tends to be more restricted to the immediate vicinity of the veins as has been commonly observed for phloem-loaded solutes (Geiger, 1975). We tested the idea that the green zones may represent accumulations of mineral nutrients and the yellow zones depletions; however, the results show that the green zones in these leaves with special patterns do not contain elevated levels of mineral nutrients with the yellow zones being depleted. This ap- 
plies not only to the minerals $\mathrm{P}, \mathrm{Ca}, \mathrm{Mg}, \mathrm{Mn}$, $\mathrm{Fe}, \mathrm{Cu}, \mathrm{B}, \mathrm{Zn}$ and $\mathrm{Na}$ but also $\mathrm{S}$, which provides an estimate of protein (Maranville, Mattern and Clark, 1984), but starch as well. Girdling does increase the $\mathrm{K}$ and Mo levels in both the veinal and interveinal regions. Therefore, no redistribution is apparent within the senescing leaf when export of minerals from the leaf to the pods is blocked. In contrast to these patterned soybean leaves, several elements are present at higher concentrations in the green zones of Eucalyptus leaves with a similar pattern induced by alkaline calcareous soils (Mazzolini et al., 1982).

General significance-The pods are able to induce senescence of a soybean leaf even though the petiole has been girdled to prevent exodus of nutrients; however, the yellowing is mainly interveinal leaving green zones along the main veins. The significance of the pod-induced senescence of the girdled leaf is discussed elsewhere in terms of the mechanism of pod-induced senescence (Noodén and Murray, 1982; Noodén, 1984). Girdling of depodded plants does not induce the senescence syndrome. Depodding, however, not only blocks the net breakdown of foliar starch but prevents the net loss of minerals from the leaf blades (Derman et al., 1978; Wood, Murray and Noodén, unpubl. data) which demonstrates the importance of the pods. The studies reported here demonstrate that chlorophyll breakdown (a component of the senescence syndrome) is not necessarily accompanied by mineral nutrient or starch withdrawal. Nonetheless, breakdown and redistribution of the leaf components including protein are legitimately considered components of the senescence syndrome (e.g., see Thimann, 1980; Noodén, 1984). Thus, it is of interest that chlorophyll breakdown can be uncoupled from net starch breakdown or loss of the mineral nutrients. In addition, soybean mutants which senesce (die) but do not undergo the usual yellowing have been reported (Kahanak et al., 1978; Noodén, 1984). This further suggests that senescence may consist of several parallel processes which can be uncoupled (Noodén, 1984).

\section{LITERATURE CITED}

BenNer, J. L., AND L. D. NoOdÉN. 1984. Translocation of photosynthate from soybean leaves to the pods during senescence. Biochem. Physiol. Pflanzen 179: 269-275.

Deluca D'Oro, G. M., AND V.S. Trippi. 1980. Modelos de envejecimiento foliar en especies de dicotiledoñeas. Phyton 38: 49-57.
Derman, B. D., D. C. Rupp, AND L. D. NoOdén. 1978. Mineral distribution in relation to fruit development and monocarpic senescence in Anoka soybeans. Amer. J. Bot. 65: 205-213.

GeIger, D. R. 1975. Phloem loading. In M. H. Zimmermann and J. A. Milburn [eds.], Transport in plants I. Phloem transport. Encycl. Pl. Physiol., New Series, Vol. 1, pp. 395-431. Springer-Verlag, Berlin.

Greenway, H., AND A. GunN. 1966. Phosphorus retranslocation in Hordeum vulgare during early tillering. Planta 71: 43-67.

HeMBERG, T. 1975. ABA as an inhibitor of $\alpha$-amylase from Aspergillus and Bacillus subtilis. Physiol. Pl. 35: 11-15.

Kahanak, G. M., Y. Okatan, D. C. Rupp, and L. D. NoODÉN. 1978. Hormonal and genetic alteration of monocarpic senescence in soybeans. Pl. Physiol. 61(suppl.): 26.

Klingman, G. C., AND F. M. Ashton. 1975. Weed science: principles and practices. Wiley-Interscience Publ., NY.

LEOPOLD, A. C. 1961. Senescence in plant development Science 134: 1727-1732.

, E. Niedergang-Kamien, ANd J. JANick. 1959. Experimental modification of plant senescence. Pl. Physiol. 34: 570-573.

LINDOO, S. J., AND L. D. NoodêN. 1976. The interrelation of fruit development and leaf senescence in 'Anoka' soybeans. Bot. Gaz. 137: 218-223.

- AND L. D. NOODÉN. 1977. Behavior of the soybean senescence signal. Pl. Physiol. 59: 1136-1140.

Loenwing, F. W. 1951. Mineral nutrition in relation to the ontogeny of plants. In E. Troug [ed.], Mineral nutrition of plants, pp. 343-356. Univ. of Wisconsin Press, Madison, WI.

Maranville, J. W., P. J. Mattern, and R. B. Clark 1984. Estimation of sulfur in grain by $\mathrm{x}$-ray fluorescence spectrometry and its relation to sulfur and amino acids of field crops. Crop Sci. 24: 303-305.

Mazzolini, A. P., C. A. Anderson, P. Y. Ladiges, and G. J. F. LeGGE. 1982. Distribution of mineral elements in green and chlorotic leaf tissue of Eucalyptus obliqua L'Hérit., determined with a scanning proton microprobe. Aust. J. P1. Physiol. 9: 261-269.

Mishra, S. D., And B. K. Gaur. 1972. Control of senescence in betal leaves by depetiolation. Exp. Geront. 7: 31-35.

NAKATA, S., AND A. C. LeOPOLD. 1967. Radioautographic study of translocation in bean leaves. Amer. J. Bot. 54: 769-772.

Neumann, P. M., A. T. Tucker, and L. D. Noodén. 1983. Characterization of leaf senescence and pod development in soybean explants. P1. Physiol. 72: 182185.

NoOdÉN, L. D. 1980 . Senescence in the whole plant. In K. V. Thimann [ed.], Senescence in plants, pp. 219258. CRC Press, Boca Raton, FL.

- 1984. Integration of soybean pod development and monocarpic senescence. Physiol. Pl. 62: 273-284. . 1985. Regulation of soybean senescence. In R. Shibles [ed.], Proc. World Soybean Res. Conf. III, pp. 891-902. Westview Press, Boulder, CO.

, AND A. C. LEOPOLD. 1978. Hormonal control of senescence and abscission. In D. S. Letham, T. J. Higgins and P. B. Goodwin [eds.], Phytohormones and related compounds, Vol. II, pp. 329-369. Elsevier, Amsterdam. 
NoOdÉn, L. D., AND B. J. Murray. 1982. Transmission of the monocarpic senescence signal via the xylem in soybean. Pl. Physiol. 69: 754-756.

NOODÉN, L. D., AND J. W. ThOMPSON. 1985. Aging and senescence in plants. In C. E. Finch and E. Schneider [eds.], Handbook of the biology of aging, 2nd ed., pp. 105-127. Van Nostrand Reinhold, NY.

Okatan, Y., G. M. Kahanak, AND L. D. NoodÉN. 1981. Characterization and kinetics of soybean maturation and monocarpic senescence. Pl. Physiol. 52: 330-338.

ScotT, W. O., AND S. R. AldRICH. 1970. Modern soybean production, pp. 145-146. S and A Publ., Champaign, IL.
SimON, E. W. 1967. Types of leaf senescence. Symp. Soc. Exp. Biol. 21: 215-230.

SinClaiR, J. B. [ed.]. 1982. Compendium of soybean diseases. The American Phytopathological Society, St. Paul, MN.

Sprague, H. E. 1964. Hunger signs in crops, 3rd ed. David McKay Co., NY.

ThimanN, K. V. 1980. The senescence of leaves. In K. V. Thimann [ed.], Senescence in plants, pp. 85-116. CRC Press, Boca Raton, FL.

Williams, R. F. 1955. Redistribution of mineral elements during development. Ann. Rev. Pl. Physiol. 6: $25-42$. 